\title{
Product R\&D Rivalry and Quality Policy in an International Industry Composed of Firms from Capitalist and Post-Communist Countries
}

\author{
Yasunori Ishii \\ Graduate School of Economics, Waseda University, Shinjuku-ku, Tokyo, Japan \\ Email: yishii@waseda.jp
}

How to cite this paper: Ishii, Y. (2018). Product R\&D Rivalry and Quality Policy in an International Industry Composed of Firms from Capitalist and Post-Communist Countries. Open Journal of Political Science, 8, 291-304.

https://doi.org/10.4236/ojps.2018.83021

Received: March 28, 2018

Accepted: July 22, 2018

Published: July 25, 2018

Copyright $\odot 2018$ by author and Scientific Research Publishing Inc. This work is licensed under the Creative Commons Attribution International License (CC BY 4.0).

http://creativecommons.org/licenses/by/4.0/

\begin{abstract}
Modeling an international mixed duopoly composed of a private firm from a capitalist country (CC), and a state firm from a post-communist country (PCC) that choose outputs and product qualities under quality policies of their governments, we analyze the firms' output-quality rivalry and the governments' quality policies. We find that when the PCC's state firm is partially or perfectly privatized, an increase in the quality subsidy of each country raises its firm's output, product quality and market share, but decreases those of its rival firm, and both the quality policies of the CC and PCC are the subsidy policies. However, when the PCC's state firm is completely nationalized, while a change in the quality subsidy of the CC has the similar effects as those mentioned above, a change in the quality subsidy of the PCC has no effect on the firms' outputs, product qualities and market shares, which means that the optimal quality policy of the CC is the subsidy policy, but that of the PCC is to do nothing.
\end{abstract}

\section{Keywords}

International Mixed Duopoly, Post-Communist Country, Quality Competition, Quality Policy

\section{Introduction}

During the past 30 years, the world economy has experienced two significant changes in many international industries. One is a change in international industrial structures, and the other is a change in international economic policies, which have combined to establish the present world economy.

Since the collapse of the former Communist bloc in 1991, all post-communist 
countries (PCCs, hereafter) have tried to privatize their state firms, most of which have been partially or perfectly privatized, and promoted almost all these state firms to participate in international industries. Consequently, numerous international industries have converted to mixed industries that are composed of state firms of post-communist countries and private firms of capitalist countries (CCs, hereafter).

On the other hand, since new World Trade Organization codes generally prohibited direct trade policies such as export subsidies and/or import tariffs, process and/or product $\mathrm{R} \& \mathrm{D}$ policies have obtained central positions as international economic policies. Especially, as the number of firms conducting product $R \& D$ investment has increased, the product $R \& D$ policies have gained popularity in many international industries.

Clearly, these descriptions demonstrate that it is important and useful to consider at last two changes mentioned above when analyzing firms' output-quality competition and governments' economic policies in some international industries. However, as is well known, only a few articles have introduced such international economic changes into their models when modeling international mixed industries ${ }^{1}$. The main purpose of this article is to model an international mixed industry that introduces such two changes indicated above and to investigate firms' output-quality choices and governments' product R\&D subsidy policies, because it is reckless to propose firms' product $\mathrm{R} \& \mathrm{D}$ policies without proper investigations.

To my knowledge, by modeling third-country trade duopolies in which firms from developing and developed countries decide endogenously their product qualities and their governments implement quality policies for their domestic firms, Ishii (2013), Ishii (2014), and Taba \& Ishii (2016) have analyzed firms' output-quality decisions and governments' product R\&D policies. However, since their models have supposed international industries composed of only CCs' private firms, it is not certain whether their propositions are also true in international mixed industries composed of PCC's state firms and CC's private firms. Therefore, we establish a model of an international mixed industry in which the PCC's and CC's firms conduct endogenous output-quality decisions and their governments implement product $R \& D$ policies.

Our basic model is established by converting one of two CCs' private firms in the third-country trade model constructed by the above-mentioned three articles into a PCC's state firm and by adding some necessary arrangements. Thus, an international mixed duopoly in this article is composed of a partially (or perfectly) privatized state firm of the PCC and a private firm of the CC that decide endogenously their product qualities as well as outputs. It is assumed in our article that the PCC's state firm acts to maximize a positive linear combination (a weighted average) of its profit and social welfare, while the CC's private firm ${ }^{1}$ For articles analyzing the privatization of state firms in international mixed industries, see Fjell \& Pal (1996), Pal \& White (1998), Bárcena-Ruiz \& Garzón (2005), Chang (2005), and Chao \& Yu, (2006), for example, although their purposes are quite different from ours. 
aims to maximize its profit ${ }^{2}$. Furthermore, to make our model more realistic, we replace restrictive Hoteling-type demand functions adopted by some existing articles with more generalized demand functions presented by Yasunori Ishii [(Ishii, 2013) and (Ishii, 2014)] $]^{3}$.

We find that the privatization degree of the PCC's state firm plays significant roles in determining the firms' outputs and product qualities, and the governments' quality policies. When the PCC's state firm is partially or perfectly privatized, an increase in the quality subsidy of each country raises its firm's output, product quality, and market share, but decreases those of its rival firm. It follows that both the optimal quality policies of the CC and PCC are the subsidy policies in this case. However, when the PCC's state firm is completely nationalized, while a change in the quality subsidy of the CC has the similar effects as those mentioned above, a change in the quality subsidy of the PCC has no effect on the firms' outputs, product qualities, and market shares. Consequently, the optimal quality policy of the CC is the subsidy policy, but that of the PCC is to do nothing to its firm.

The rest of this article is organized as follows. In Section 2, we establish a three-stage game model of an international mixed duopoly that satisfied the abovementioned conditions. In Sections 3 and 4, we analyze firms' output decisions and quality choices, respectively. In Section 5, we discuss the optimal quality policies implemented by the CC's and PCC's governments. In Section 6, we present some concluding remarks on the propositions presented in this article and suggestions for future researches.

\section{Basic Model and Assumptions}

Suppose an international mixed duopoly in which a CC's private firm and a PCC's partially or perfectly privatized state firm produce differentiated goods in their own countries and supply all of their products to the PCC, and the governments of these countries give quality subsidies (taxes when negative) to their firms by considering firms' product qualities, respectively. While the CC's private firm maximizes its profit $\pi$, the PCC's privatized state firm maximizes a positive linear combination $Z$ of its profit $\Pi$ and PCC's social welfare $W$, that is, $Z=\lambda \Pi+(1-\lambda) W$, and both firms endogenously determine their outputs and product qualities. It is assumed that the privatization degree $\lambda(0 \leq \lambda \leq 1)$ of the PCC's state firm is predetermined by the PCC's government in order to focus on relationships between firms' quality rivalry and governments' quality policies. When $0<\lambda \leq 1 \quad(\lambda=0)$ holds, the PCC's state firm is partially or perfectly pri${ }^{2}$ For the objective of a PCC's state firm, Yasunori Ishii [(Ishii, 1986) and (Ishii, 1990)], and Chang \& Ishii (2014) supposed the maximization of income per worker. However, in this article we adopt the hypothesis proposed by Matsumura (1998).

${ }^{3}$ Hotelling-type demand functions have the following restrictive features: 1) they are not derived by solving the consumer utility maximization problem under budget constraints; 2) they depend on the assumption that consumers choose at most one unit (zero or one) of a good. For more detailed arguments, see Yasunori Ishii [(Ishii, 2013) and (Ishii, 2014)]. 
vatized (completely nationalized). Both the CC's and the PCC's governments implement quality subsidies to maximize their own social welfare, $W$ and $W$, respectively.

In an international mixed industry as is mentioned above, while the CC's consumers don't consume any goods, the PCC's consumers do both goods produced by the two firms. Therefore, the PCC's consumers explicitly appreciate the product qualities of these goods by their utility functions including product qualities as independent variables. To capture these features, by considering the utility function proposed by Ottaviano, Tabuch, \& Thisse (2002) and Ishii (2014), we define the utility function of the representative consumer in the PCC as

$$
u=A(x+X)+\alpha(q x+Q X)-a\left(x^{2}+X^{2}\right) / 2-b x X+z, \quad(b<a)
$$

where $x(X)$ and $q(Q)$ are the output and product quality of the CC's private firm (PCC's state firm), $z$ is demand for the aggregated good (numéraire) from other industries, and $A, a, b$ and $\alpha$ are positive constants. Then, the well-known utility maximization problem under a budget constraint leads to the inverse demand functions of the CC's private firm and the PCC's state firm:

$$
p=A+\alpha q-a x-b X, \quad P=A+\alpha Q-a X-b x,
$$

where $p$ and $P$ are the prices of the goods produced by the CC's and PCC's firms, respectively. Here, $b<a$ implies that the effect of a change in the output of a firm on its own price is larger than the cross-effect of a change in its output on the rival's price. If the firms' product qualities are exogenously given, the above inverse demand functions reduce to usual ones that depend on only outputs ${ }^{4}$.

When firms decide outputs and product qualities, they incur production and quality costs. Hence, by using the demand functions in (2), profits of the CC's and PCC's firms, $\pi$ and $\Pi$, are defined as

$$
\begin{gathered}
\pi=(A-a x-b X+\alpha q) x-c x-h(q)+s q, \\
\Pi=(A-a X-b x+\alpha Q) X-C X-H(Q)+S Q,
\end{gathered}
$$

where $s$ and $S$ are the unit quality subsidies (taxes when negative) of the CC's and PCC's firms, $c$ and $C$ are their unit production costs, and $h(q)$ and $H(Q)$ are their quality cost functions with plausible features expressed as $h^{\prime}(q)>0$, $h^{\prime \prime}(q)>0, H^{\prime}(Q)>0$, and $H^{\prime \prime}(Q)>0$, respectively.

On the other hand, considering that the CC's firm exports all its output to the PCC in the third-country trade model, the social welfare, $w$ and $W$, of the CC and PCC are given by

$$
\begin{gathered}
w=\pi-s q \\
W=C S+\Pi-S Q
\end{gathered}
$$

\footnotetext{
${ }^{4}$ Although these demand functions seem to be restrictive at first glance, they are the most general and realistic functions at the present stage of quality economics that analyzes firms' endogenous quality choices, because they eliminate the restrictive features inherent in Hotelling-type demand functions described in the endnote 3.
} 
where $C S$ is the consumer's surplus in the PCC defined as $A(x+X)+\alpha(q x+Q X)-a\left(x^{2}+X^{2}\right) / 2-b x X-p x-P X$ under the utility function given by (1).

Using notations and equations presented above, we summarize the firms' output-quality decisions and governments' policy implementations as followings, that is, the CC's private firm chooses $x$ and $q$ to maximize $\pi$ defined as (3.1), the PCC's state firm determines $X$ and $Q$ to maximize $Z$ constituted by considering $\Pi$ in (3.1) and $W$ in (4.2) as

$$
Z=\lambda \Pi+(1-\lambda) W
$$

and the CC's and PCC's governments implement $s$ and $S$ to maximize $W$ and $W$ given by (4.1) and (4.2), respectively. It is immediately clear that when the PCC's state firm is completely nationalized ( $\lambda=0)$, the objective function of the PCC's state firm coincides with that of the PCC's government.

To solve the abovementioned problem, we suppose that the governments and firms in the CC and PCC play a three-stage game. In the first stage, the CC's and PCC's governments implement the optimal quality subsidies. In the second stage, the CC's and PCC's firms choose their product qualities, $q$ and $Q$, and in the third stage they decide their outputs, $x$ and $X$, to maximize their objective functions, respectively. We assume that the firms and governments act as Cournot followers in all decision stages. We solve this three-stage game problem by using the backward induction method.

\section{Firms' Output Choices in the Third Stage}

In this section, we analyze the optimal output choices of the CC's private firm and the PCC's state firm in the third stage. Since these firms engage in Cournot quantity competition, given that the privatization degree $\lambda$ of the PCC's firm and both firms' product qualities $q$ and $Q$ have already been determined in the earlier stages, the two firms uncooperatively choose $x$ and $X$ to maximize $\pi$ and $Z$, respectively. Thus, the industrial equilibrium conditions in the output-choosing third stage are characterized by

$$
\begin{gathered}
-2 a x-b X-c+A+\alpha q=0, \\
-\lambda b x-a(1+\lambda) X-C+A+\alpha Q=0,
\end{gathered}
$$

where (6.1) and (6.2) are the first-order conditions and reaction functions of the CC's private firm and PCC's state firm, respectively.

Under the conditions of the demand and cost functions described in the previous section, we obtain

$$
\begin{aligned}
& \pi_{x x}=\partial^{2} \pi / \partial x^{2}=-2 a<0, \pi_{x X}=\partial^{2} \pi / \partial X \partial x=-b<0, \\
& Z_{X X}=\partial^{2} Z / \partial X^{2}=-a(1+\lambda)<0, Z_{X x}=\partial^{2} Z / \partial x \partial X=-\lambda b \leq 0 .
\end{aligned}
$$

Thus, the firms' second-order conditions are satisfied and their reaction curves are both negatively sloped, which implies that the firms' outputs are strategic substitutes for each other. Furthermore, since $\pi_{x x}<0, Z_{X X}<0$, and 
$\pi_{x x} Z_{X X}-\pi_{x X} Z_{X x}>0$ hold, the industry equilibrium is regarded as partially stable at the industry equilibrium. Then, by solving (6.1) and (6.2) simultaneously with respect to $x$ and $X$, we can derive the outputs chosen by the CC's private firm and the PCC's state firm in the third stage ${ }^{5}$.

As is clear from (6.2), $\Pi_{X}$ and $W_{X}$ have different signs at the industry equilibrium. Then, considering $W_{X}-\Pi_{X}=a X>0$ for $0<\lambda<1$, we obtain at the industry equilibrium:

$$
\Pi_{X}<0<W_{X}
$$

It follows that the output of the partially privatized PCC's state firm is larger than that maximizing its profit but smaller than that maximizing the PCC's social welfare. Thus, the privatized PCC's state firm faces well-known dilemma: when it increases output to raise social welfare, it reduces its profit, and vice versa. Of course, the perfectly privatized or nationalized PCC's state firm is free from such a dilemma.

On the other hand, (6.1) and (6.2) combine to show that both of the firms' optimal outputs depend on their product qualities, because (6.1) and (6.2) include them, $q$, and $Q$, as parameters. Thus, we can obtain the effects of changes in firms' product qualities on their outputs from (6.1) and (6.2).

Totally differentiating both sides of (6.1) and (6.2) with respect to $x, X, q$, and $Q$, respectively, and arranging the results, we obtain

$$
\left[\begin{array}{cc}
-2 a & -b \\
-\lambda b & -a(1+\lambda)
\end{array}\right]\left[\begin{array}{c}
\mathrm{d} x \\
\mathrm{~d} X
\end{array}\right]=\left[\begin{array}{c}
-\alpha \mathrm{d} q \\
-\alpha \mathrm{d} Q
\end{array}\right]
$$

Thus, from (9) we derive the following results:

$$
x_{q}=a \alpha(1+\lambda) / D, X_{q}=-\lambda \alpha b / D, x_{Q}=-\alpha b / D, X_{Q}=2 a \alpha / D
$$

where $D=\pi_{x x} Z_{X X}-\pi_{x X} Z_{X x}>0$. Therefore, (a) when the PCC's state firm is partially or perfectly privatized $(0<\lambda \leq 1)$, (10) presents

$$
x_{q}>0, X_{q}<0, x_{Q}<0, X_{Q}>0 \text {, }
$$

but, (b) when the PCC's state firm is completely nationalized $(\lambda=0),(10)$ reduces to

$$
x_{q}>0, X_{q}=0, x_{Q}<0, X_{Q}>0 .
$$

Therefore, (10.1) and (10.2) are paraphrased as the following proposition:

Proposition 1: 1) When the PCC's state firm is partially or perfectly privatized $(0<\lambda \leq 1)$, while an amelioration (deterioration) in the product quality of each firm increases (decreases) its output, it decreases (increases) that of its rival firm. 2) When the PCC's state firm is completely nationalized $(\lambda=0)$, though a rise (fall) in the product quality of the PCC's firm raises (reduces) its output but reduces (raises) its rival's output, a rise (fall) in the product quality of the CC's firm raises (reduces) its output, but gives no ef-

${ }^{5}$ For the partial differentiations, we use the following abbreviations: $x_{k}=\partial x / \partial k, \pi_{k}=\partial \pi / \partial k$, $\pi_{k K}=\partial^{2} \pi / \partial K \partial k, Z_{K K}=\partial^{2} Z / \partial K^{2}$, and so on. 


\section{fect to its rival's output.}

In addition to this proposition, (10) also indicates that the privatization degree of the PCC's state firm affects significantly the effects of changes in firms' product qualities on their outputs. While the effects of a change in the product quality of the PCC's state firm on the firms' outputs are both independent of the privatization degree of the PCC's state firm, the effects of a change in the product quality of the CC's private firm on the firms' outputs are both dependent on the privatization degree of the PCC's state firm. Especially, the effect of a change in the product quality of the CC's private firm on the PCC's firm's output becomes zero when the privatization degree of the PCC's state firm is zero, which clarifies that the perfect nationalization of the PCC's state firm severs the relationship between the product quality of the CC's firm and the output of the PCC's state firm. Evidently, these results are quite different from those found by Taba \& Ishii (2016) that model an international industry composed of only CC's firms.

Furthermore, considering $b<a$ and $0 \leq \lambda \leq 1$, (10) also presents the following relationships:

$$
0<\left|X_{q}\right|<X_{Q}, 0<\left|x_{Q}\right|<x_{q}, 0<\left|x_{Q}\right|<X_{Q}, 0<\left|X_{q}\right|<x_{q} .
$$

Hence, (11) leads to the next proposition:

Proposition 2: 1) The optimal output of each firm responds more sensitively to a change in its own product quality than to a change in its rival's product quality. 2) Arise in the product quality of every firm increases not only its own output but also the industry total output, and vice versa.

Obviously, proposition 2 reconfirms the plausibility of the well-known reasoning that the direct effect of a change in the product quality of each firm on its output is usually larger than the cross-effect on its rival's output, as adopted by many existing studies on firms' endogenous quality decisions. It follows that a rise in the product quality of every firm improves the PCC's economic welfare, ceteris paribus, which would be welcomed by the residents of the PCC.

\section{Quality Decisions in the Second Stage}

In the second stage, the CC's private firm and the PCC's state firm decide their product qualities, $q$ and $Q$, to maximize $\pi$ and $Z$, respectively, given the privatization degree of the PCC's state firm, the rival's quality choice, and other exogenous variables. Therefore, by taking into consideration that the governments' optimal quality subsidies, $s$ and $S$, have already been determined in the first stage and that the firms' outputs, $x$ and $X$, will be chosen optimally in the next stage, the industrial equilibrium in the second stage is expressed by

$$
\begin{gathered}
\left(\alpha-b X_{q}\right) x-h^{\prime}(q)+s=0, \\
\lambda\left(a-b x_{Q}\right) X+(1-\lambda)\left(a X+a x x_{Q}\right)-H^{\prime}(Q)+\lambda S=0,
\end{gathered}
$$

where (12.1) and (12.2) are the first-order conditions and reaction functions of the CC's private firm and the PCC's state firm in the quality-setting second stage, 
respectively. It is assumed that $h^{\prime \prime}(q)$ and $H^{\prime \prime}(Q)$ are both sufficiently large so as to satisfy the firms' second-order conditions for maximizing their objective functions, because the maximization problems of the firms become meaningless if such the conditions wouldn't be satisfied. Then, we have

$$
\begin{gathered}
\pi_{q q}=\alpha\left(1+\lambda b^{2} / D\right) x_{q}-h^{\prime \prime}(q)<0, \\
Z_{Q Q}=\left\{\lambda\left(a+\alpha b^{2} / D\right)+(1-\lambda) \alpha\left(X_{Q}-\alpha b x_{Q} / D^{2}\right)\right\} X_{Q}-H^{\prime \prime}(Q)<0 .
\end{gathered}
$$

Furthermore, considering (10), (12.1) and (12.2), we obtain $\pi_{q Q}<0$ and $Z_{Q q}<0$. Then, these results and (13) combine to imply that the firms' product qualities are strategic substitutes for each other, and thus the firms' reaction curves in the second stage are both downward sloping. Moreover, as many existing studies have accepted, if the effect of a change in the firm's product quality on its marginal objective function dominates the cross-effect, then the industry equilibrium is locally stable, because we have $\pi_{q q}<0, Z_{Q Q}<0$, and $\pi_{q q} Z_{Q Q}-\pi_{q Q} Z_{Q q}>0$. Hence, solving (12.1) and (12.2) simultaneously with respect to $q$ and $Q$, we obtain the firms' optimal product qualities.

One of interesting issues to be examined in an international mixed industry that endogenously determines firms' product qualities through their quality rivalry is how changes in the CC's and PCC's governments' quality subsidies affect the firms' product qualities. Clearly, since (12.1) and (21.2) include the quality subsidies of these countries as exogenous variables, we can derive such the effects of changes in these quality subsidies on the firms' product qualities by using these equations.

Totally differentiating the industry equilibrium conditions given by (12.1) and (12.2) with respect to $q, Q, s$, and $S$, we obtain

$$
\left[\begin{array}{cc}
\pi_{q q} & \pi_{q Q} \\
Z_{Q q} & Z_{Q Q}
\end{array}\right]\left[\begin{array}{l}
\mathrm{d} q \\
\mathrm{~d} Q
\end{array}\right]=\left[\begin{array}{c}
-\mathrm{d} s \\
-\lambda \mathrm{d} S
\end{array}\right] .
$$

Then, considering $\pi_{q q}<0, Z_{Q Q}<0, \pi_{q Q}<0$ and $Z_{Q q}<0$, we derive from (14):

$$
q_{s}=-Z_{Q Q} / \Delta, Q_{s}=Z_{Q q} / \Delta, q_{S}=\lambda \pi_{q Q} / \Delta, Q_{S}=-\lambda \pi_{q q} / \Delta,
$$

where $\Delta=\pi_{q q} Z_{Q Q}-\pi_{q Q} Z_{Q q}>0$. Thus, dividing (15) into two cases, we can demonstrate that 1) when the PCC's state firm is partially or perfectly privatized $(0<\lambda \leq 1)$, (15) leads to

$$
q_{s}>0, Q_{s}<0, q_{S}<0, Q_{S}>0,
$$

and 2) when the PCC's state firm is completely nationalized ( $\lambda=0)$, (15) reduces to

$$
q_{s}>0, Q_{s}<0, q_{S}=0, Q_{S}=0 .
$$

Therefore, (15.1) and (15.2) are paraphrased as the following proposition:

Proposition 3: 1) When the PCC's state firm is partially or perfectly privatized $(0<\lambda \leq 1)$, an increase in a quality subsidy in every country improves the product quality of its own firm, but it degrades that of its rival 
country's firm, and vice versa. 2) When the PCC's state firm is completely nationalized $(\lambda=0)$, a rise in the CC's quality subsidy raises its firm's product quality and reduces its rival firm's product quality, and vice versa, whilst a change in the PCC's quality subsidy has no effect on the product qualities of the two firms.

Proposition 3 says, in more plain words, that the privatization degree of the PCC's state firm also plays a significant role in determining the effects of changes in governments' product subsidies on their firms' product qualities. When a privatization degree of the PCC's state firm is positive, a change in the quality subsidy in every country gives a positive (negative) effect to the product quality of its domestic (foreign) firm. On the other hand, when the privatization degree of the PCC's state firm is zero, both the political effects of a change in the quality subsidy of the PCC on the firms' product qualities are zero.

Now, since we have (10.1), (10.2), (15.1) and (15.2), we can discuss the effects of changes in the quality subsidies of the PCC and the CC on their firms' outputs by using these equations. We also investigate these problems by considering whether the PCC's state firm is partially (perfectly) privatized or completely nationalized, as done in the previous sections. When the PCC's state firm is partially or perfectly privatized, (10.1) and (15.1) combine to present

$$
\begin{aligned}
& x_{s}=x_{q} q_{s}+x_{Q} Q_{s}>0, x_{S}=x_{q} q_{S}+x_{Q} Q_{S}<0, \\
& X_{s}=X_{q} q_{s}+X_{Q} Q_{s}<0, X_{S}=X_{q} q_{S}+X_{Q} Q_{S}>0 .
\end{aligned}
$$

On the other hand, when the PCC's state firm is completely nationalized, considering (10.2) and (15.2), we obtain

$$
x_{s}=x_{q} q_{s}>0, x_{S}=0, X_{s}=X_{Q} Q_{s}<0, X_{S}=0 .
$$

Consequently, we summarize (16.1) and (16.2) as the following proposition:

Proposition 4: 1) When the PCC's state firm is partially or perfectly privatized $(0<\lambda \leq 1)$, an increase in the quality subsidy of every country increases the firm's output of its own country, and decreases that of its rival country, and vice versa. 2) When the PCC's state firm is completely nationalized $(\lambda=0)$, a rise in the CC's quality subsidy raises the firm's output of its own country, and reduces that of its rival country, and vice versa, while a change in the PCC's quality subsidy has no effects on the outputs of the $P C C$ 's and CC's firms.

According to Propositions, 3, and 4, we can summarize the political effectiveness of the quality subsidy policy in the PCC and the CC on the outputs, the product qualities and the market shares of their firms belonging to the international mixed industry as followings. In the case where the PCC's state firm is partially or perfectly privatized, an increase in the quality subsidy of every country raises the output, the product quality and the market share of its own firm and reduces those of its rival firm. Thus, both the quality subsidy policies of the PCC and the CC are effective in controlling firms' behaviors in international mixed industries. However, when the PCC's state firm is completely nationa- 
lized, the quality subsidy of the CC still maintains its political effectiveness on the firms' actions, but the quality subsidy of the PCC loses its political effectiveness on the firms' decision makings, which means that the quality policy of the PCC entirely loses its effectiveness in an international mixed industry.

Proposition 4 in this article is contrary to that found by Taba \& Ishii (2016). Using a model of an international duopoly composed of only CC's private firms, they demonstrate that an increase in the quality subsidy of every country always increases the firm's output of its own country, and decreases that of its rival country, and vice versa. They do not appeal the case where the quality subsidy policy of one country loses its value. Of course, this difference between their and our propositions seems come from that of the model structures.

Generally, it is quite common to suppose that the PCC's government does not implement its quality policy if its political effects on firms' product qualities and outputs are completely null. Clearly, Proposition 4 demonstrates, together with Proposition 3, that the quality subsidy of the PCC has no effects on the firms' product qualities and outputs when the PCC's state firm is perfectly nationalized. Therefore, from these propositions it would be plausible to suggest that the optimal quality policy of the PCC is to implement zero subsidy in the case where its state firm is perfectly nationalized, while it is to set a positive subsidy when its state firm is not perfectly nationalized.

However, the abovementioned political suggestions would not be derived from any existing articles that assume constant quality mixed industries. Moreover, such political suggestions about quality policies would not be accepted without rigorous analyses of the quality policies set by the governments. Therefore, in the next section we rigorously examine the optimal quality policies of the PCC's and CC's governments by using our model ${ }^{6}$.

\section{Product R \& D Policy in the First Stage}

In the first stage, the CC's and PCC's governments implement their product quality subsidies, $s$ and $S$, to maximize their welfare, $w$ and $W$, defined as (4.1) and (4.2), given the rival country's quality subsidy and the firms' first-order conditions in the second and third stages. Thus, taking into consideration that the profits of the CC's and PCC's firms are given by (3.1) and (3.2), that (6.1) and (6.2) hold in the third-stage equilibrium, and that (12.1) and (12.2) are satisfied in the second-stage equilibrium, we have the first-order conditions for maximizing $w$ and $W$ by the CC's and the PCC's governments as

$$
\begin{gathered}
w_{s}=\pi_{X} X_{q} q_{s}+\pi_{X} X_{Q} Q_{s}+\pi_{Q} Q_{s}-s q_{s}=0, \\
W_{S}=W_{X} X_{q} q_{S}+W_{X} X_{Q} Q_{S}-S Q_{S}=0,
\end{gathered}
$$

respectively. We assume, as in the previous section, that the second-order conditions for maximizing the CC's and PCC's economic welfare are satisfied and that the industry equilibrium in the first stage is stable. Then, using (17.1) and (17.2), ${ }^{6}$ Obviously, any existing articles assuming constant product qualities cannot present any political suggestions of quality policies. 
we can analyze the optimal quality policies of the CC and PCC.

In the previous sections, the optimal output and quality choices of the CC's and PCC's firms were investigated, depending on the privatization degree of the PCC's state firm. Similarly, we also discuss the optimal quality policies of the CC's and PCC's governments by considering whether the privatization degree of the PCC's state firm is positive or zero.

First, when the PCC's state firm is partially or perfectly privatized $(0<\lambda \leq 1)$, (10.1), (15.1) and (16.1) hold at the industry equilibrium in the third and second stages, respectively. Hence, substituting these equations into (17.1) and (17.2), and rearranging the results, we obtain

$$
\begin{gathered}
s=\left(\pi_{X} X_{q} q_{s}+\pi_{X} X_{Q} Q_{s}+\pi_{Q} Q_{s}\right) / q_{s}>0, \\
S=\left(W_{X} X_{q} q_{S}+W_{X} X_{Q} Q_{S}\right) / Q_{S}>0 .
\end{gathered}
$$

On the other hand, if the PCC's state firm is completely nationalized $(\lambda=0)$, we have (10.2), (15.2) and (16.2) at the industry equilibrium in the third and second stages. Thus, substituting these conditions into (17.1) and (17.2) and rearranging the results, we present

$$
\begin{gathered}
s=\left(\pi_{X} X_{Q} Q_{s}+\pi_{Q} Q_{s}\right) / q_{s}>0, \\
S=0 .
\end{gathered}
$$

Therefore, (18.1), (18.2), (19.1) and (19.2) are paraphrased as the following proposition:

Proposition 5: 1) When the PCC's state firm is partially or perfectly privatized $(0<\lambda \leq 1)$, both the optimal quality policies of the CC's and PCC's governments are to give positive subsidies to their firms' product qualities; 2) When the PCC's state firm is completely nationalized ( $\lambda=0$ ), the optimal quality policy of the CC's government is to offer a positive subsidy to its own firm's product quality, while that of the PCC's government is to do nothing to its firm's product quality.

In other words, Proposition 5 says that the privatization degree of the PCC's state firm also plays a critical role in determining the CC's and PCC's optimal quality policies in an international mixed industry composed of the CC's and PCC's firms. More specifically, this proposition indicates that the optimal quality subsidies of the CC and PCC are both positive and finite when the PCC's state firm is at least privatized.

Usually, it would be very common to suppose that when a rise in a quality subsidy of every country increases the market share of its own country in an international mixed industry, the endless increase in the quality subsidy of every country is regarded as profitable from a practical point of view for enlarging its market share. However, Proposition 5a denies such a conjecture from a standpoint of social welfare maximization.

Moreover, one might conjecture that the optimal quality subsidy of the PCC's government is always zero by considering the definition of the PCC's social wel- 
fare, $W$, defined as (4.2), because the same amount of quality subsidy of the PCC's government appears twice in the definition of $W$ as positive and negative terms. However, Proposition $5 \mathrm{~b}$ rejects such a conjecture and appeals that the optimal quality subsidy of the PCC's government is positive when the PCC's state firm is partially or perfectly privatized, though it is zero when the PCC's state firm is completely nationalized. This result comes from the fact that even the same amount of quality subsidy gives the different economic implications to the PCC's state firm and its government except for the case where the PCC's state firm is completely nationalized.

Once again, it is immediately obvious that Proposition $5 b$ is also quite different from the proposition of the quality policies presented by Taba \& Ishii (2016). While Taba and Ishii's proposition demonstrates that the optimal quality policies for the governments are always to give positive subsidies to their own firms, our Proposition 5b shows a possibility of a zero quality-subsidy. Therefore, these arguments show that it is very reckless to apply some political suggestions conjectured from a study adopting an industrial structure to another industry with a different industrial structure.

\section{Concluding Remarks}

In this article, we first establish a three-stage game model of an international mixed duopoly in which a CC's private firm and a PCC's state firm endogenously determine their product qualities and outputs, and their governments implement quality policies to reinforce their firms' international competitive power, respectively. In our model, it is assumed that the privatization degree of the PCC's state firm is predetermined to focus on firms' endogenous output-quality choices and governments' quality policies. The CC's private firm maximizes its profit, while the PCC's state firm maximizes the positive linear combination of its profit and the PCC's social welfare. The governments and firms play a three-stage game, that is, the governments determine the optimal quality policies in the first stage, and the firms decide their product qualities in the second stage and choose their outputs in the third stage.

Then, we analyze how the firms choose their optimal outputs and product qualities, how the governments implement the optimal quality policies, how the governments' quality policies affect the firms' output and product quality choices, and how the predetermined privatization degree of the PCC's state firm influences the firms' output-quality choices and the governments' optimal quality policies. Moreover, in order to clarify the originality of this article, we compare our propositions with the corresponding ones presented by Taba \& Ishii (2016) that analyzes the similar problems by using a model of international duopoly composed of only the CC's private firms.

We find that the privatization degree of the PCC's state firm plays a significant role in determining the firms' optimal quality-output choices, the governments' optimal quality policies, the signs and sizes of the political effects of 
changes in government quality subsidies on the firms' quality-quantity levels. Although we summarize the above findings as the five propositions in the previous sections, we here refer to them again to emphasize their notable features.

It is shown that, when the PCC's state firm is partially or perfectly privatized, 1) a rise in the product quality of every firm increases its own output, but decreases its rival firm's output, and vice versa; 2 ) an increase in the quality subsidy in every country improves its own firm's product quality, but deteriorates that of its rival firm, and thus 3) an increase in the quality subsidy in every country increases its own firm's market share, but reduces that of its rival firm in an international mixed industry.

On the other hand, we demonstrate that when the PCC's state firm is completely nationalized, 1) although a rise in the product quality of the PCC's firm increases its output and decreases its rival's output and vice versa, an improvement (deterioration) in the product quality of the CC's firm raises (reduces) its output, but does not change its rival's output; 2) an increment in the CC's quality subsidy raises its firm's product quality and reduces its rival firm's product quality and vice versa, whilst a change in the PCC's quality subsidy has no effect on the product qualities of the two firms, and then 3) a rise in the CC's quality subsidy increases the firm's market share of its own country, and reduces that of its rival country and vice versa, whilst a change in the PCC's quality subsidy has no effects on the market shares of the PCC's and CC's firms.

Furthermore, we also clarify that 1) when the PCC's state firm is partially or perfectly privatized, both the optimal quality policies of the CC's and PCC's governments are to give the subsidies to their firms, and 2) when the PCC's state firm is completely nationalized, the optimal quality policy of the CC's government is a subsidy policy, while the optimal quality policy of the PCC's government is to do nothing to its firm's product quality.

As is already described in this article, Taba \& Ishii (2016) established a model of the international duopoly composed of only the CC's firms that endogenously decide their product qualities and outputs and found that a rise in quality subsidy of every country always raises the output, product quality and market share of its own firm, and reduces those of its rival firm, and, thus, both the optimal quality policies of these countries are always subsidy policies. Therefore, it is clear that all propositions in this article are contrary to the correspondent ones derived by Taba \& Ishii (2016). Especially, they failed to show that all the firms' optimal output-quality levels and the governments' optimal quality polices depend on the privatization degree of the PCC's state firm and that when the PCC's state firm is completely nationalized, the optimal quality policy of the PCC's government is to do nothing to its firm's product quality.

Of course, it is self-evident that nobody can derive proper political suggestions about quality policies from articles studying mixed industries that assume firms' constant product qualities, because such articles do not analyze governments' quality policies. Moreover, as is clarified in this article, it is quite thoughtless to conjecture political suggestions that are applied to international mixed indus- 
tries composed of CC's private and PCC's state firms by referring to just findings presented by articles based on international industries consisting of only CC's private firms. These arguments demonstrate that in order to suggest appropriate policies in real industries we must establish suitable models that reflect main characteristic features observed in such industries ${ }^{7}$.

\section{References}

Bárcena-Ruiz, J. C., \& Garzón, M. B. (2005). International Trade and Strategic Privatization. Review of Development Economics, 9, 502-513. https://doi.org/10.1111/j.1467-9361.2005.00290.x

Chang, L., \& Ishii, Y. (2014). Privatization and Employment in Post-Communist Countries. Theoretical Economics Letters, 4, 579-583. https://doi.org/10.4236/tel.2014.47073

Chang, W. (2005). Optimal Trade and Privatization Policies in an International Duopoly with Cost Asymmetry. Journal of International Trade and Economic Development, 14, 19-42. https://doi.org/10.1080/0963819042000333234

Chao, C.-C., \& Yu, E. (2006). Partial Privatization, Foreign Competition, and Optimum Tariff. Review of International Economics, 14, 87-92. https://doi.org/10.1111/j.1467-9396.2006.00562.x

Fjell, K., \& Pal, D. (1996). A Mixed Oligopoly in the Presence of Foreign Private Firms. Canadian Journal of Economics, 29, 737-743. https://doi.org/10.2307/136260

Ishii, Y. (1986). On the Theory of International Trade between Capitalist and Labor-Managed Countries. Economics Letters, 21, 195-198. https://doi.org/10.1016/0165-1765(86)90064-9

Ishii, Y. (1990). On the Theory of East-West Trade under Uncertainty. Journal of Economics, 52, 267-283. https://doi.org/10.1007/BF01227525

Ishii, Y. (2013). On the State Advertising Policy under Quality Information Bias. Review of Development Economics, 17, 571-583. https://doi.org/10.1111/rode.12051

Ishii, Y. (2014). Quality-Price Competition and Product R\&D investment Policies in Developing and Developed Countries. Economic Record, 90, 197-206. https://doi.org/10.1111/1475-4932.12076

Ishii, Y. (2018). Quality Rivalry in An Industry Composed of Private and Public Firms under Privatization. Open Journal of Social Sciences, 6, 29-42. http://www.scirp.org/journal/iss

Matsumura, T. (1998). Partial Privatization in Mixed Duopoly. Journal of Public Economy, 70, 473-483. https://doi.org/10.1016/S0047-2727(98)00051-6

Ottaviano, G., Tabuch, T., \& Thisse, J.-F. (2002). Agglomeration and Trade Revised. International Economic Review, 43, 409-436.

Pal, D., \& White, M. (1998). Mixed Oligopoly, Privatization, and Strategic Trade Policy. Southern Economic Journal, 65, 264-281. https://doi.org/10.2307/1060667

Taba, Y., \& Ishii, Y. (2016). Product R\&D Investment Policies in an International Duopoly. Review of Development Economics, 20, 574-582. https://doi.org/10.1111/rode.12241

${ }^{7}$ As regards the effects of a change in the privatization policy on the firms' product qualities, see Ishii (2018). 